\title{
Análisis de supervivencia de cáncer colorrectal metastásico según la localización del tumor primario
}

- Pedro Luis Ramos, María Athenas Ramos Escalante, Diana Silva, Ómar Hoyos

Oncológica Oncocare (Bogotá, D.C.)

Introducción: el impacto de la localización del tumor primario en cáncer colorrectal metastásico sugiere un peor pronóstico para pacientes con localización en colon derecho. El propósito de este estudio es estimar la supervivencia global y libre de progresión en una cohorte de cáncer colorrectal metastásico según la localización del tumor primario.

Materiales y métodos: se incluyeron pacientes desde enero de 2008 a septiembre de 2017. Se construyeron curvas de supervivencia con el método de Kaplan-Meier, se compararon con el método de rangos logarítmicos y se realizó un análisis de regresión de rangos proporcionales de Cox.

Resultados: se identificó un total de 72 pacientes. La edad promedio fue 62 años. El 54,17\% de sexo masculino y localización en colon izquierdo 49 (68,06\%). El KRAS fue no mutado en el 36\%; los sitios más frecuentes de metástasis fueron peritoneal (41,6\%) y hepático (57\%). La quimioterapia más usada fue en combinación con bevacizumab (59,7\%). La mediana de supervivencia libre de progresión fue de 14,2 meses y la supervivencia global fue de 26,9 meses. La supervivencia global y libre de progresión se disminuye en pacientes con cáncer de colon derecho HR 2,28 (IC95\% 1,20-4,34; $p=0,012$ ) y 1,77 $(1,09-3,49 ; p=0,011)$. Si hay tres o más sitios de metástasis HR 2,89 $(1,19-7,05)$ y 2,48 $(1,33-13,02)$. La supervivencia libre de progresión se reduce en KRAS mutado HR 1,64 (1,11-2,43; $p=0,03)$.

Conclusiones: la sobrevida global y libre de progresión se disminuye en tumores de colon derecho y con tres o más sitios de metástasis; y la supervivencia libre de progresión se reduce en KRAS mutado. 